\title{
Benign Tonsillar Neoplasm
}

National Cancer Institute

\section{Source}

National Cancer Institute. Benign Tonsillar Neoplasm. NCI Thesaurus. Code C3594.

A non-metastasizing neoplasm that arises from the tonsil. 